vane, which was typically 80 per cent, was determined by comparing the intensities of the chemiluminescent omissions associated with the $\mathrm{O}+\mathrm{NO}$ (ref. 6), $\mathrm{N}+\mathrm{N}$ (ref. 7) or $\mathrm{H}+\mathrm{NO}$ (ref. 8) reactions above and below the vane. The sensitivity of the suspension was determined by calculating the moment of inertia of the vane and measuring its period of oscillation when mounted on the fibre. It was possible to detect a difference of pressure of 0.05 dyne $/ \mathrm{cm}^{2}$.

Vanes of silver, copper, nickel and platinum were used; in no case could a deflexion attributable directly to atom recombination be detected, but in all cases there was a slow deflexion with a time constant of about 5 sec (the natural period of the vane-fibre system was about $0.5 \mathrm{sec}$ ). This deflexion increased with the atom concentration (but not lincarly) and was independent of the total pressure for a given atom concentration. It was concluded that this deflexion was associated with unequal temperatures of the surfaces of the vane due to the heat released by recombination on the uncoated surface of tho vane. Such effects have been discussed in connexion with the "Crookes radiometer', ${ }^{\prime}, 10$. The time constant of the deflexion corrosponded to the time for the vane temperature to reach a steady state.

Since the smallest force which could be detected was equal to the force exerted by the atoms which hit the active surface and remained on the surface to recombine, it was concluded that molecules of oxygen, nitrogen and hydrogen formed by recombination on silver, copper, nickel and platinum surfaces do not leave the surface with an averago of more than twice the normal thermal velocity.

F. S. IJARKIN

B. A. Thrush

Department of Physical Chemistry, University of Cambridge.

${ }^{2}$ Reeves, R. R., Mannella, G. G., and Harteck, P., J. Chem. Phys., 32, $946 ; 33,636(1960)$

Wood, B. J., and Wise, H., J. Phys. Chem., 65, 1.976 (1961).

'Linnett, J. W., and Marsden, D. G. H., Proc. Roy. Soc., A, 234, 489, 504 (1956).

4 Kaufman, F., and Kelso, J. R., J. Chem. Phys., 27, 1209 (1957).

$\therefore$ Kistiakowsky, G. B., and Volpi, G. G., J. Chem. Phys., 27, 1141 (1957).

- Kaufman, H., Proc. Roy. Soc., A, 247, 123 (1958).

Berkowitz, J., Chupka, W. A., and Kistiakowsky, G. B., J. Chem. Phys.. $25,457(1956)$

- Clyne, M. A. A., and Thrush, B. A., Trans. Farad. Soc., 57, 1305 (1961).

${ }^{y}$ Loeb, I. B., Kinetic Theory of Gases (McGraw-Hill, New York, 1927).

${ }^{\circ}$ Marsh, H. F., Loeb), I. B., and Condon, E., J. Opt. Soe. Amer., 11, 257 (1925).

\section{Heat of Formation of the Difluoromethylene Radical}

Majer and Patrick ${ }^{1}$ have recently reported a value for the heat of formation of $\mathrm{CF}_{2}$ which differs appreciably from that reported by Margrave et $a l .^{2}$ and regresses toward values from the older literature. This heat has been deduced from electron impact studies on $\mathrm{C}_{6} \mathrm{H}_{5} \mathrm{CF}_{3}$ and $\mathrm{C}_{6} \mathrm{H}_{4} \mathrm{FCF}_{3}$ and involves the appearance potentials of the $\mathrm{C}_{6} \mathrm{H}_{5} \mathrm{~F}^{+}$and $\mathrm{C}_{6} \mathrm{H}_{4} \mathrm{~F}_{2}+$ ions, respectively. Since those ions are not formed directly from the parent molecules, it is obviously dangerous to utilize appearance potentials for thermochemical calculations of any except the most qualitative nature, and a detailed consideration of the data seems to indicate that $-17 \mathrm{kcal} / \mathrm{mole}$ is only a positive limit for the heat of formation of $\mathrm{CF}_{2}$.

A spontaneous unimolecular rearrangement of $\mathrm{C}_{6} \mathrm{H}_{5} \mathrm{CF}_{3}{ }^{+}$ to yield $\mathrm{C}_{6} \mathrm{H}_{5} \mathrm{~F}^{+}+\mathrm{CF}_{2}$ in large yield seems improbablo but, if this happens, it must involve an excited state of the ion. A cyclic intermediate ( 7 -membered ring) would require the breaking of two carbon-carbon bonds and no doubt a considerable activation energy. If the first step in the fragmentation reaction of $\mathrm{C}_{6} \mathrm{H}_{5} \mathrm{CF}_{3}$ were:

$$
\mathrm{C}_{6} \mathrm{H}_{5} \mathrm{CF}_{3}+e \rightarrow \mathrm{C}_{6} \mathrm{H}_{5} \mathrm{CF}_{2}{ }^{+}+\mathrm{F}+2 e
$$

and the second step were cither a spontaneous unimolecular rearrangement:

$$
\mathrm{C}_{6} \mathrm{H}_{5} \mathrm{CF}_{2}+\ldots ; \mathrm{C}_{6} \mathrm{H}_{5} \mathrm{~F}^{+}+\mathrm{CF}
$$

or an ion-molecule process (highly improbable at the low. pressures used):

$$
\mathrm{C}_{6} \mathrm{H}_{5} \mathrm{CF}_{2}++\mathrm{F} \rightarrow \mathrm{C}_{6} \mathrm{H}_{5} \mathrm{~F}^{+}+\mathrm{CF}_{2}
$$

then the appearance potential of $\mathrm{C}_{6} \mathrm{H}_{5} \mathrm{~F}^{+}$will be essentially that of $\mathrm{C}_{6} \mathrm{H}_{5} \mathrm{CF}_{2}{ }^{+}$since the second and third reactions are undoubtedly exothermic. Majer and Patrick ${ }^{1}$ did not consider the possibility of CF as a product. In either case. there seems little chance that the energy liberated in the second spontaneous step could be utilized to help make the first step to go in the normal ionization chamber.

One would estimate the energy needed for ionization of typical fluorocarbons to fall in the range 9-10 eV, and for breaking a $\mathrm{C}-\mathrm{F}$ bond to fall in the $4-5 \mathrm{eV}$ range $^{3-5}$. The sum of these factors (13-15 eV) compares favourably with the $13.35 \mathrm{eV}$ appearance potential for $\mathrm{C}_{6} \mathrm{H}_{5} \mathrm{~F}^{+}$from $\mathrm{C}_{6} \mathrm{H}_{5} \mathrm{CF}_{3}$, the $13 \cdot 15 \mathrm{eV}$ appearance potential for $\mathrm{C}_{6} \mathrm{H}_{4} \mathrm{~F}_{2}{ }^{+}$ from $p-\mathrm{C}_{6} \mathrm{H}_{4} \mathrm{FCF}_{3}$ and the $13.75 \mathrm{eV}$ appearance potential for $\mathrm{C}_{6} \mathrm{H}_{4} \mathrm{~F}_{2}{ }^{+}$from $m-\mathrm{C}_{6} \mathrm{H}_{4} \mathrm{FCF}_{3}$ as reported by Majer and Patrick $^{1}$, and thus tends to support the postulate that the apparent energy required for forming these ions is primarily determined by a roaction liko (1) and that the exothermicities of reactions like (2) and (3) or those involving a cyclic intermediate are not being properly considered. Since the dissociation energy for a $\mathrm{C}_{6} \mathrm{H}_{5}-\mathrm{CX} X_{3}$ bond is approximately $10-30 \mathrm{kcal} / \mathrm{mole}$ less than for a $\mathrm{C}_{6} \mathrm{H}_{5}-\mathrm{X}$ bond, one should correct the appearance potentials accordingly and this yields $\Delta \mathrm{H}_{f}\left(\mathrm{CF}_{2}\right) \approx-35 \pm$ $10 \mathrm{kcal} / \mathrm{mole}$, in good agreement with earlier work.

There seems to be little support for the $13 \cdot 35 \mathrm{eV}$ ioniza. tion potential of $\mathrm{CF}_{2}$ reported by Reed and Snedden ${ }^{6}$ since this would limit the $\mathrm{C}-\mathrm{C}$ bond energy in $\mathrm{C}_{2} \mathrm{~F}_{4}$ to a maximum of about $46 \mathrm{kcal} / \mathrm{mole}$, which is much too low and incompatible with the properties of $\mathrm{C}_{2} \mathrm{~F}_{4}$.

Another piece of evidence for a more stable $\mathrm{CF}_{2}$ radical comes from the patent of Farlow $^{7}$, who prepared $\mathrm{C}_{2} \mathrm{~F}_{4}$ from $\mathrm{CF}_{4}$ and graphite in an induction-heated furnace. From these data, Stull ${ }^{8}$ has calculated: $\Delta \mathrm{H}_{1}^{0}=$ $-46 \pm 5 \mathrm{kcal} / \mathrm{mole}$ for $\mathrm{CF}_{2}$.

Department of Chemistry,

University of Wisconsin, Madison.

1 Majer, J. R., and Patrick, C. R., Nature, 192, 866 (1961),

Margrave, J. L., J. Chem. Phys., 31, 1432 (1959). Brewer, L., Margrave,

J., Porter, R., and Wieland, K., J. Phys. Chem., 65, 1913 (1961).

Cottrell, T. L.. Rond Jissociation Energies, second ed. (Butterworths, Tondon, 1956).

- Field, F. II., and Franklin, J. L., Ilectron Impact Phenomend (Academi. Pross, New York, 1957).

${ }^{5}$ Majer, J. R., J. Appl. Chem. 11, 141 (1961).

- Reed, J. H., and Snedden, W., Trans, Farad. Soc, 54, 304 (1957).

7 larlow, M. W., U.S. Patent 2,709,192 (May 24, 1955).

${ }^{8}$ J.A.N.A.F. Thermochemical Tables, edit. by Stull, D. R., March 31, 1961.

\section{Orientation of Benzoic Acid adsorbed on} Nickel

THE concept of aromatic systems interacting with metal surfaces has been used to explain data obtained by a variety of techniques. Suhrman and Schulz ${ }^{1}$, using thin. film electrical resistance measurements, concluded that electrons are transferred to a nickel adsorbant surface by adsorbed benzene, triphenylmethane and naphthalene. The relatively low heat of adsorption of benzene on nickel powder was interpreted by $\mathrm{Yu}$ et $a l .^{2}$ on the basis of the energy needed to destroy the aromatic ring. Blomgren et $a l .^{3}$, in investigating adsorption at the mercury-aqueou. acid solution interface using the electrocapillary method. explained the amounts adsorbed as resulting from por. pendicular orientations for straight chain aliphatic compounds and parallel orientations for planar aromatic substances. By determining the amount of adsorption from aqueous solution of various aromatic substances on to solid electrodes by bulk-phase depletion measurements. Conway et al. ${ }^{4}$ concluded that the molecular orientation was probably flat. 